\title{
El giro ontológico en las lecturas de la Naturaleza: propuestas de intervención didáctica'
}

\author{
The Ontological Turn in the Readings of the Nature: \\ Proposals of Didactic Intervention
}

\author{
AITANA MARTOS GARCÍA \\ Universidad de Almería \\ España \\ aitmartos@gmail.com
}

(Recibido: 05-O9-20I7; aceptado: 2I-IO-2OI7)

Resumen. En los actuales momentos de crisis ambiental y social se requiere una respuesta integrada, a escala supranacional, planetaria incluso, cuyo reto principal es pasar de una mentalidad antropocéntrica a otra ecocéntrica, que respete y preserve la Naturaleza. Este impulso debe venir guiado por diversas corrientes sociales $y$ de pensamiento. La lectura, en esta orientación, es un arma estratégica: su cometido es (re)significar la realidad, dando un significado renovado a todo lo que venimos categorizando como lecturas naturistas. Se revisa, pues, la incidencia del giro antológico en el abordaje de las lecturas de la naturaleza y el papel de las nuevas narrativas del agua. En el ámbito de intervención didáctica, se proponen criterios y buenas prácticas de intervención, basadas en tres pilares: promover la cultura vernácula del agua, fomentar programas de sensibilización y utilizar las propuestas ecofeministas.

Palabras clave: cultura del agua; lecturas de la Naturaleza; imaginarios; ecología; ecofeminismo; ontología.
Abstract. During our present environmental and social crises, an integrated response is required at a supranational and even planetary level. The main challenge is to move from an anthropocentric to an ecocentric mentality that respects and preserves nature. This impulse must be guided by diverse social and thought currents. Reading, in this orientation, is a strategic weapon: its task is to (re) signify reality, giving a renewed meaning to all that we have categorized as naturist readings. We review, therefore, the incidence of the anthological turn in the approach of readings on nature and the role of new narratives of water. In the field of didactic intervention, criteria and good practices of intervention are proposed, based on three pillars: to promote the vernacular culture of water, to promote programs of sensitization, and to use ecofeminist proposals.

Keywords: water culture; readings of nature; imaginary; ecology; ecofeminism; ontology.

\footnotetext{
${ }^{\text {I }}$ Para citar este artículo: Martos García, Aitana (20I8). El giro ontológico en las lecturas de la Naturaleza: propuestas de intervención didáctica. Alabe 17. [www.revistaalabe.com]

DOI: IO.I5645/Alabe20I8.I7.I
} 
Hemos sacrificado los viejos dioses inmateriales, y ocupamos el templo con el dios Mercado.

Sólo redefiniendo nuestra relación con el agua y reconociendo su lugar esencial y sagrado en la naturaleza podremos comenzar a rectificar los errores que hemos cometido

C. Barlow

\section{El Giro Ontológico y Narratológico como marco para abordar la Cultura del Agua en sus implicaciones sociales y educativas}

La frase que el presidente de Uruguay Mújica pronunció en la ONU en 2OI3, da un diagnóstico muy acertado de la situación. Habla, en apariencia metafóricamente, de tres elementos: "los viejos dioses inmateriales", el templo y el dios Mercado. Se podría pensar que se estaba refiriendo a los viejos valores humanistas, pero, a nuestro juicio, es muy reveladora la distinción: los viejos dioses (plural) / el dios Mercado (singular), que ocupa un espacio que llama "templo". También es muy significativo el término "sacrificar", quiere decir que esos "dioses" han sido liquidados para poner en su lugar el dios Mercado.

Sabemos desde Eliade (I967) que los símbolos casa-cuerpo-mundo son equivalentes, de modo que con templo no puede referirse sino a nuestra "oikos", la casa común, es decir, a la ecología, al planeta como nuestra única morada. La alusión a los dioses en plural tampoco es casual: se trata de entender a la Naturaleza no como algo inerte, sino con vida, personificada en estos "dioses" intangibles que pueblan las mitologías y las religiones.

Tales ideas no son ocurrencias de un político, vienen de los albores de la Humanidad: a través del animismo, que procuraba "objetivar los seres de la naturaleza en figuras reconocibles”, como Eolo y el viento (Descola, 20I2), pero también de corrientes filosóficas como el hilozoísmo (Fructuoso, 2006), que entendía que la materia misma tenía vida. Por ejemplo, cuando hablamos actualmente de agua, formulada de forma genérica, no deja de ser una abstracción moderna (Linton, 20IO), que no se compadece con la experiencia múltiple de la humanidad.

Los pueblos han "vivenciado" el agua, pero en sus innumerables facetas y dimensiones, cuando la bebe, o se baña o la usa ritualmente, por tanto no tiene sentido para un sumerio o un hombre medieval hablar del agua al margen de sus contextos, y, por tanto, 
sabe percibir o escuchar el agua conforme a este polifonía de voces (Bajtin,I974), y al sinfín de sus formas.

\section{I.I El giro ontológico y narratológico}

En la base de esta concepción de las ontologías múltiples está el repensar las relaciones naturaleza/cultura, al amparo de lo que se ha llamando el giro ontológico en la antropología contemporánea:

Las críticas de ambos autores sobre la universalidad del concepto de naturaleza conllevan una cuestión sobre su extensión y sus efectos en la producción etnográfica. Esto no quiere decir que para ellos la noción de naturaleza sea obsoleta o que habría que rechazarla rotundamente; al contrario, comentan que lo que está en juego no es su existencia, sino su división binaria que opone y separa lo humano como un factor externo. El par naturaleza/cultura se posiciona como el eje constitutivo del gran divisor de la ontología occidental que es necesario desmantelar para afrontar otras formas de pensar híbridamente las relaciones sociales, culturales y entre seres (llámense espíritus, dioses). Son estas otras formas híbridas las que constituirían diferentes ontologías, o sea maneras de organizar los principios cosmológicos y de sociabilidad que contrastarían con el patrón divisor de la modernidad (González Varela, 20I5, 39-6).

En efecto, la antropología pos-estructural ha propiciado un giro ontológico, al poner en cuestión muchas de las categorías, fruto, según autores de esta antropología de índole perspectivista, como E. Viveiros (2004), o P. Descola y B. Latour (Reynoso,20I5). Sería el caso de la preconcepción occidental de que hay una única Naturaleza y muchas cultural, siendo así que en la Amazonía muchas cosmologías indígenas entienden que hay no una, sino "muchas naturalezas" y, además, tienen una visión inclusiva de la cultura, que incluye a todos los seres (personas, animales, cursos de agua...).

Es lo que se llama el multinaturalismo (Viveiros, 2004) que, en conjunción con el perspectivismo, ha estudiado la América indígena bajo estos presupuestos que desmitifican algunos estereotipos, y, en este caos, justifican que se pueda incluir en un mismo plano al hombre, el animal, la planta y lo no-humano, como un río.

Esto daría un sentido propio a estas leyendas naturistas: el espíritu del agua que protagoniza las leyendas, por ejemplo, del río Magdalena (Faust, 2004) en Colombia, no es que sea una alegoría o personificación del río, sino que se comporta como un ser humano o un animal, tiene voluntad, afectos, ira o sentido moral o retributivo respecto a las acciones humanas. Martínez Dueñas explica acertadamente esta naturaleza del espíritu del agua que desafía los postulados del racionalismo europeo:

L'eau, l'un des éléments centraux de cet article, une entité qui, pour les modernes, est un objet ( $\mathrm{H}_{2} \mathrm{O}$, un nonhumain sans intériorité, esprit, volonté ou culture), possède à la fois des caractéristiques d'objet (un liquide inerte et inanimé) et de sujet (doté d'un esprit et de volonté) pour 
de nombreux Puracéens, ce qui en fait une entité particulière qui n’existe pas dans l'épistémè moderne.

Celle-ci définit en effet le monde à travers une division précise entre sujet (humain) et objet (entité vivante ou non vivante sans subjectivité, volonté ou culture) [Latour 2007]. Pour les modernes, l'eau est seulement un objet ( $\mathrm{H}_{2} \mathrm{O}$ sans esprit, subjectivité ou volonté), et l'absence de cette dichotomie dans d'autres mondes (considérés comme d'autres cultures par les modernes) s'explique par le mythe ou par un manque de connaissances objectives de la nature (Martínez Dueñas, 20I2a: 40)

Así pues, las ontologías múltiples deben entenderse en el sentido de que todos, humanos y no humanos, comparten un mismo paisaje específico, un espacio corográfico -una kora o territorio con su alma propia o "genius loci", por tanto, todos tienen voluntad y están envueltos en una misma realidad, que las mitologías a menudo denominan con invocaciones a la sacralidad, como los lucus o bosques sagrados. Pero que también la modernidad, como veremos más de renombrar con metáforas como "la venganza de Gaia" (Lovelock, 2007).

Por tanto la dicotomía sujeto/objeto no tiene sentido en estas cosmologías, y por eso mismo la visión del agua como objeto o masa inerte sería inconcebible y en todo caso insuficiente, pues no daría cuenta de todas estas formas complejas de creencias y sensibilidades.

De forma bastante paralela, en la narratología posestructural se produce una amplitud del campo y un cuestionamiento de los enfoques anteriores, particularmente el análisis formal de los textos sin un estudio en profundidad de las prácticas o las creencias, pasando por la recepción posterior de estas textualizaciones (Honko, 2000). Eso supone vincular las leyendas naturalistas a sus contextos sociales y a las creencias, por ejemplo, del campesinado.

Esta diversidad de contextos y de prácticas explicarían las ontologías múltiples, el gran número de leyendas de seres mitológicos de agua que encontramos en el Norte de la península ibérica (Martos Núñez, 2OII) o, en el contexto americano, las personificaciones múltiples del citado Río Magdalena: La Madremonte, La madre de agua, El Mohan, La Llorona, etc. ((Morales, 2002), de forma que tales símbolos campesinos revelarían una memoria y unos usos culturales muy amplios, que tiene que ver con encantos, con el oro y las relaciones interétnicas, y el recuerdo de las poblaciones prehispánicas. La poética de la leyenda es capaz de transmutar todo esto en fábulas consistentes que se perpetúan, dotadas de gran fuerza, como La Llorona (Martos García, 20I5)

\section{I.2. Poéticas y heterotopías}

Es imprescindible, pues, una revisión de la cultura del agua con ayuda de las diversas perspectivas de estudio y paradigmas científicos, a fin de facilitar una visión poliédrica, holística de esta realidad sumamente compleja. 
La cultura del agua debe entenderse como el conjunto de prácticas, imaginarios, artefactos y tecnologías que cada cultura ha generado, estableciendo el agua no solo como un recurso básico sino como una construcción cultural compleja a caballo entre lo material y lo inmaterial, sus usos y sus significados, es decir, como una realidad que solo puede entenderse de forma holística.

Al contrario de la pretensión cientifista o tecnocrática de que el agua es solo una clase de materia, homogénea, igual en todas partes, y que carece de historia o de memoria, veremos que el agua el bien más preciado de una comunidad, un "tesoro", como diríamos desde la simbología del agua, diverso y múltiple, y que impregna la memoria de la comunidad, a nivel local y a niveles más amplios.

Dos grandes pensadores, como Bachelard (2005) y Foucault (I986) han ayudado a esta comprensión holística, el primero al subrayar los elementos poética y simbólicos del agua, y el segundo al crear el concepto de "heterotopía”, es decir, de un "lugar-otro", alternativo, que es lo que realmente son muchos lugares de aguas encantadas, como los jardines, fuentes o estanques con historias de ninfas u ondinas, o bien las playas o baños de recreo, en un plano más profano y actual. En todo caso, los sueños y las heterotopías nos hablan de una dimensión feliz, de ritos de purificación o de momentos compartidos donde la gente bebe, nada o procura curarse, siempre en presencial del agua.

Todo ello nos lleva a la conclusión de que el agua, formulada de forma genérica, es una abstracción moderna (Silvestri, 20I5), que no se compadece con la experiencia múltiple de la humanidad, que la ha "vivenciado" y "nombrado" no como una realidad genérica sino a través de sus en múltiples facetas. Así, no es lo mismo el agua natural de una montaña o un valle que la de nadar, beber o purificarse, como no es igual el mar en calma que el de la tempestad o los acantilados peligrosos. Así, ya dentro de las culturas indígenas, aparecen con fisonomía diferenciada los espíritus del agua y de las montañas (2OII), protectores de ecosistemas, si bien habitan no en todos sino en ciertos lugares ad hoc.

Parafraseando a Bajtin (I974) podemos decir que la cultura del agua se nutriría también de la polifonía y el dialogismo de voces y creencias, el agua que da vida, y, a la par, el agua y otros paisajes que provocan miedo (Tuan, 20I3) y que se asocian a la muerte.

Una ontología tecnológica o material del agua pretende ignorar la dimensión cultural y centrarse en el "mundo profano", donde los acontecimientos son inmanentes, no trascienden a nada, y tienen una explicación científica racional. Sin embargo, la experiencia religiosa está ligada a la percepción de lo numénico (Otto, I985), y por tanto cabe identificar el agua como ejemplo de epifanía, de revelación de lo majestuoso del numen, en todas sus propiedades, como lo que sobrecoge, fascina, desborda, etc. Los mitos acuáticos y sus personajes o avatares, tienen muchos de estos rasgos, solo hay que hay que recordar los pueblos sumergidos por inundaciones mágicas.

En su dimensión histórico-cultural, el agua, como han descrito Bachelard, Eliade y otros tantos, tiene asociaciones evidentes con los orígenes (y final) de la vida, con lo femenino y lo materno, o con animales que nos evocan lo húmedo, como la serpiente. 
La infancia está jalonada, como nos recuerda Bachelard, de recuerdos de tormentas, de arroyos claros o de vistas de un río o un mar, es decir, de heterotopías felices. Como se demuestra en la película de Truffaut de 1969 , El niño salvaje, hemos olvidado el placer ancestral de beber agua, con la fruición con que lo hace el niño salvaje.

Silvestri (2015), abundando en esta idea de la multiplicidad de las aguas, recuerda "que no es la misma la del arroyo de la campaña que la del mar en Moby Dick. Existen aguas claras, fugitivas, superficiales, pero también turbias, mezcladas: la facilidad del agua para componerse con otros elementos nos introduce a imaginaciones barrosas, en las que la mano "piensa", donde el agua es a la vez amante y rebelde, como en los ríos sudamericanos. Podríamos sumar otros estados del agua: los paisajes helados antárticos, las aguas subterráneas, el agua en los ciclos atmosféricos" (20I5:4).

\section{Los Imaginarios de la Naturaleza y las nuevas narrativas del Agua.}

Barlow (2008) pondera la necesidad de una mejor comprensión de los ámbitos comunes del agua a través de lo que llama una "nueva narrativa", porque, en sintonía con lo que declaraba M. Mújica en la ONU, argumenta que en poco tiempo los valores de exclusión, posesión, monopolio y lucro personal o empresarial del ultracapitalismo, han reemplazado los valores de inclusión, propiedad colectiva y capital comunitario, tópicos de los ámbitos comunes del procomún (Lafuente, 20O7). Por tanto, se hace precisa una contranarrativa, que contrapese las narrativas dominantes, es decir, la idea del agua como una mercancía que se debe comerciar y vender al mejor postor en el mercado abierto (Barlow, 2008:27). Dicha nueva narrativa debería basarse en estos principios:

I) Proclamar al agua como Bien Común

2) Adoptar la narrativa de una Democracia de la Tierra

3) Proteger el agua a través de la conservación y la ley

4) Tratar las cuencas hidrográficas como ámbitos comunes

5) Reivindicar el control comunitario sobre las fuentes de agua locales

6) Defender la soberanía de las comunidades y la nación respecto del agua

7) Adoptar un modelo fundado en la justicia respecto del agua, no en la caridad

8) Reclamar el abastecimiento público y tarifas justas

9) Consagrar el derecho al agua en las constituciones nacionales y en un Convenio de Naciones Unidas

Io) Usar y ampliar la doctrina del fideicomiso público para proteger al agua (Barlow, 2008: 27-40).

Ahora bien, defender todos estos principios programáticos no implica que usemos solamente una información detallada al respecto, hay que promover el discurso narrativo. Conforme al giro ontológico y narrativos que venimos glosando, hay que "reencantar" o 
"remitificar" la naturaleza, y no hay mito si no hay relato, y, sobre todo, ‘ remitiéndonos a Benjamin (I994), hay que separar información de narración. En efecto, según Benjamin (I933), la narración es la experiencia se comparte de boca en boca, y, como tal, no es una sucesión o acumulación de datos, sino un trenzado de acontecimientos urdido a partir de símbolos consistentes para la comunidad.

De ahí la crítica de Benjamin a la sociedad de la información, al periodismo, como fábrica de información/opinión que conforma conciencias e imposibilita la experiencia plena -que en el mito nunca es instantánea, fugaz o fragmentada, como la que impulsan los media- de estas narraciones primordiales. Otro elemento esencial del mito es el tempo, la experiencia es lo contrario de la prisa, de los ciudadanos (pos) modernos como "sujeitos ultra-informados, trans-bordantes de opiniões e superestimulados, (...) sempre em atividade, porque estamos sempre mobilizados, não podemos parar. E, por não podermos parar, nada nos acontece” (Bondía Larrosa, 2002:24). La experiencia tiene mucho que ver con la prueba, el viaje, la salida, y eso nos lleva al patrón de los mitos heroicos, y la Naturaleza de convierte no en un decorado sino en el propio ámbito iniciático, como es el mar en los relatos de Conrad o Melville.

Tales principios vendrían a situarse en las creencias o "axiologías” propias de una comunidad democrática avanzada del s.XXI acerca de la función que debe tener la Naturaleza y, en particular, el agua. Así, adoptar la narrativa de una democracia de la Tierra (Shiva, 2006) supone, a fin de cuentas, adoptar el mismo planteamiento de la ecología profunda. Ésta, según Merchán (2OII), se opone al antropocentrismo: ni la Naturaleza ni el agua son un simple almacén de materias primas a nuestra libre disposición. Esto enlaza con un planteamiento propio del biocentrismo, es decir, de una mentalidad que coloca en un plano de igualdad a todos los seres vivos y busca no contraponer Naturaleza y Civilización, sino conciliar las demandas humanas con las propias de los ecosistemas diversos en los que vivimos.

Si hablamos por tanto de igualdad y de respeto a la Naturaleza, esto es de ecocentrismo, y de derecho también a la diversidad cultural, entonces se hace preciso un nuevo paradigma cultural, como el de la Democracia de la Tierra (Shiva, 20o6), que frene la depredación de la naturaleza y la expansión del consumismo, y entonces vuelven a cobrar sentido las historias de genius loci, de guardianes del agua que protegen los enclaves naturales y los defiendan de la intrusión humana o del acaparamiento. Este nuevo paradigma se puede entender en términos de resacralizar la Naturaleza bajo una visión holística de la vida (Capra, 2004), huyendo de la concepción mecanicista (Merchán, 2OII). En consecuencia, las leyendas y narraciones literarias que ponen en primer plano la naturaleza deben ser tomadas como auténticas ecoficciones, reveladoras de una experiencia valiosa acerca de la Naturaleza, interpretable a la luz de los nuevos paradigmas, como la hermenéutica y la ecocrítica.

Los imaginarios del agua van más allá de su valor como fabulaciones. Por ejemplo, la estética y las representaciones acerca de las lavanderas y otros genios del agua nos enseñan a entender el agua de forma holística, en su aspecto dadivoso y también en su 
aspecto siniestro o peligroso. También nos enseña a respetarla, a entender la contaminación y otros riesgos, como son la idea de progreso, beneficio o desarrollismo en tanto que estereotipos que oscurecen todo lo que es la cultura del agua. Las lavanderas son un ejemplo del simbolismo complejo y de los arquetipos transculturales en juego (Martos, 2OI7), pues constituyen memoria cultural que ha ido pasando de generación en generación, y de cultura en cultura, en peligro de ser transformado en un recuerdo fosilizado. De forma que convertir estas narrativas míticas en la base de las nuevas contranarrativas del agua (Barlow, 2008) sería una buena proyección de esta indagación. De hecho, las lavanderas nocturnas o la figura de Nausícaa, como princesa que hace de lavandera en $L a$ Odisea, son un contraejemplo de la proletarización del oficio, propio de la Edad Moderna, es decir, ponen de relieve los valores ecofeministas.

En última instancia, las nuevas narrativas del agua (Barlow, 2008) preconizan principios tan simples como proclamar al agua como Bien Común, y no como una mercancía más, así como reforzar el principio democrático como mejor instrumento para proteger el agua a través de la conservación y la ley. Los ríos, por ejemplo, no conocen de estados, de fronteras y de otros imaginarios sociales (Castoriadis, I999), pero en todos los testimonios culturales se aprecia siempre, ya sea de una cultura europea, semita o indoamericana, que un curso de agua natural es algo más una simple conducción para riegos o desechos industriales, y que por eso desde la Antigüedad ya tenemos manifestaciones del tópico del locus amoenus, nucleado casi siempre en torno a una fuente o ribera y un paisaje frondoso que da sombra, es decir, árboles, hierba y agua en equilibro y armonía con el hombre. En clave mítica, el río a menudo es un dios impetuoso, como Aquelóo, o el bosque sagrado está consagrado a una ninfa.

Más recientemente, son la literatura y las artes, por ejemplo, las que han dado forma a estas nuevas narrativas del agua, como la poesía del paisaje del australiano J. Kinsella (I997) o la novela del francés Mourlevat Un río al revés. Con el mismo derecho que las compañías embotelladoras de agua o la publicidad de las playas, crean miradas alternativas dirigidas a que se perciban las experiencias del agua (en suma, del medio ambiente) conforme a valores y sensibilidades mucho menos andrópicas, esto es, tratando de entender la naturaleza desde ella misma y, por tanto, en una forma que asegure más la sostenibilidad.

A este respecto, la experiencia que cabe rastrear en la obra de Kinsella es sumamente aleccionadora, con su énfasis en los valores de los aborígenes australianos y su consideración sagrada del agua y de sus "señales", los billagong, que tienen su equivalente mediterráneo en las charcas secas, bebederos, etc. Para Redondo Olmedila (2015), hay una aportación significativa de la narrativa mítica de los aborígenes australianos, que podemos comparar en un ejercicio de interculturalidad. En efecto, la palabra australiana billabong procede de un grupo de aborígenes, los wiradjuri, quienes denominaban así a zonas que habían conseguido retener el agua en verano durante más tiempo que los propios ríos, los cuales se habían secado, de ahí la importancia de nombrar estos lugares y de saber dónde estaban. Es un término que también ha sido aplicado a determinados ríos 
y ramblas y también para vados o canales que normalmente están secos excepto cuando llueve.

Lo interesante es que hay que descubrir el agua donde ya no la hay, como si estuviéramos mirando los canales de Marte. Son, pues, "aguas ocultas", que requiere un esfuerzo de comprensión integral del paisaje, la historia y el impacto de las distintas mentalidades en este recurso natural.

Las ontologías del agua nos han enseñado a entender esta profusión de seres de agua, esta exuberancia y diversidad, por ejemplo, en las distintas culturales de la península ibérica, en el tiempo y en el espacio.

El multiculturalismo lleva a relativizar las categorías culturales, en el sentido de que las culturas hídricas son diversas y diferentes. Implica también superar el eurocentrismo, por ejemplo, tenemos el concepto de multinaturalismo de Viveiros (2004). Habría no una sino distintas Naturalezas, surgidas de las relaciones entre humanos y no humanos, es algo que en cierto modo también está en el folclore europeo cuando se habla de bosques sagrados, espacios vedados al hombre precisamente por sus tabúes

W. Martínez (20I2a) habla de cómo ambos mundos, el del agua como $\mathrm{H}_{2} \mathrm{O}$ y el mundo de las creencias y cultura del agua en la zona de Purace, se amalgaman de forma singular, cuando al abastecimiento de agua se le añaden las creencias de los lugareños

Es un pensamiento hibrido que tiene en cuenta distintas formas de abordaje, la técnica pero también las creencias, se percibe bien en el temas de las aguas mineromedicinales y su relación ancestral con la curación y la magia. También en la creencia de los "guardianes del agua", en, por ejemplo, mantener a los niños lejos de fuentes o lugares donde vive el "encanto".

En consecuencia, una salida no traumática a los problemas que acarrea este giro ontológico y esta concepción de la alteridad radical, tal vez sea conciliar el pensamiento antiguo y el moderno. Por ejemplo, la idea de autoctonía (Ghidini, 20I5) es un referente interesante, porque subraya el nexo con la tierra, a un nivel telúrico. En la mitología, los autóctonos han surgido del propio suelo, de las rocas y de los árboles, y por tanto su nexo con la tierra, con lo no-humano es permanente.

Es cierto que los griegos se sentían vinculados a una identidad múltiple, a varios niveles (fratria, demo, polis, ethnos, etc.), pero mitos como el de Cécrope subrayan la hermandad de fondo entre tierra, personas y animales, pues este híbrido rey-serpiente -al igual que los monstruos que engendra Gea- viene a ser un ejemplo de una imaginería hoy exótica, pero que se basa en la teriantropía, en el nexo entre lo humano y lo salvaje, que es lo significa terion, sin las connotaciones negativas que tiene en nuestra cultura la palabra monstruo.

Por tanto, autoctonía es una noción conectable con la de la multinaturalidad, pues no solo es una manera de explicar el origen de un territorio y sus pobladores. En el mismo sentido, sustituyendo la metáfora arbórea con la acuática, Bettini (2OOI), examina la noción de "raí ‘ces", y contrapone a la imagen vertical la imagen horizontal, metáfora no del árbol, sino del río, capaz de integrar todas las aguas en un mismo curso o corrien- 
te, y de generar epifanías en torno a sus lugares sagrados: manantiales, riberas, cuevas, lagunas, etc., territorios todos ellos propicios a "encantos" (Morales, 2002).

Vemos que en estas culturas de la naturaleza, a pesar de su multinaturalismo (Viveiros,2004), hay arquetipos o referentes transculturales, como son las damas de agua, los ríos personificados, o la idea de autoctonía relacionada con la de la Madre Tierra nutricia. De hecho, las leyendas europeas de lamias se transmutan en América (cf. La Llorona, Martos, 2IO5), al igual que en la etnografía andina vemos cómo los espíritus de agua son reconocidos como las sirenas clásicas (Revilla, 2OI2).

\section{Los criterios para la intervención educativa. Buenas Prácticas}

Conciliar, como dice Martínez Dueñas (2OI2) el $\mathrm{H}_{2} \mathrm{O}$ y el espíritu del agua, supone, en primer lugar, redirigir el pensamiento unidimensional, el reduccionismo de lo material y del "dios mercado", hacia estos principios alternativos de actuación:

I. Recuperar las culturas populares y vernáculas del agua.

2. Visibilizar la naturaleza, recuperando la figura y la narrativa de los guardianes del agua en sentido amplio.

3. Recuperar el papel activo de la mujer según los postulados ecofeministas, así de otros colectivos, en la promoción de una Nueva Cultura del Agua².

A este fin, reseñemos algunas pocas buenas prácticas que puedan servir de ilustración de estas propuestas programáticas.

\section{I La cultura vernácula del agua}

Es curioso que debamos a la arquitectura una reflexión lúcida sobre la necesidad de conjugar técnica y “espíritu”, por así decir, a través de escuelas como la del genius loci (Norberg-Schulz, I979) y también en propuestas concretas de una arquitectura hilozoísta (Pérez Blanco, 2OIz) que trate de integrar el entorno y la naturaleza, huyendo de la "agresividad del cemento y la edificación" propia del boom en Occidente, en las costas, en ciudades con crecimiento desmesurado, etc., y construyendo lo que llama un "espacio sensible". Ni que decir tiene que este concepto debería aplicarse prioritariamente en la arquitectura educativa, con un concepto más flexible y ecointegrado del espacio (Adiego, 2OI2). Además, esta arquitectura hilozoísta no pretende simplemente adaptar mejor los edificios a su entorno, sino intervenir con otros criterios más amplios, como introducir lo lúdico y lo estética, y hablar de estructuras nómadas.

\footnotetext{
${ }^{2}$ Aunque el nombre de Nueva Cultura del Agua surgió en España en la década de los go al hilo de las protestas contra los trasvases, se vinculó inicialmente con la gestión, la sostenibilidad o los conflictos del agua, debemos postular una visión más holística, que incorpore precisamente ámbitos como la Historia Cultural, la Antropología, tos Imaginarios, etc. Todo ello en línea con las ideas glosadas de Barlow sobre las nuevas narrativas del agua o con la formulación de las ontologías múltiples, propias de unas culturas hídricas heterogéneas y enraizadas en patrimonios culturales muy diversos, que no pueden reducirse a los términos de la gestión o gobernanza del agua como recurso.
} 
A propósito de nomadismo, no se olvide que las narraciones tradicionales no tienen que ser a fortiori autóctonas, es decir, genuinamente locales, pues éstas son "volanderas" (en feliz expresión de A.M. Matute) por naturaleza, es decir, viajan, emigran y se transculturan continuamente (Aparaglou y Fodor, 2OI3).

Todo esto se resume en un nuevo paradigma, que parte de estudiar "el modo de habitar vernáculo, que proporciona escenarios de confort y sostenibilidad, con materiales autóctonos, saberes populares y habilidad de los pobladores en su construcción, entendiendo el habitar de una sociedad lacustre, exaltando los valores de una sencilla comunidad, rescatando las más humildes formas de expresión del Caribe y reforzando las estructuras sociales de una organización vernácula" (Chávez, 2OI2). En suma, una arquitectura "sin arquitectos", esto es, abierta a las formas tradicionales.

Todo ello es especialmente extrapolable a la cultura vernácula del agua, que debe encuadrarse en una alfabetización situadas, y formar parte de un canon inclusivo de ecolecturas, esto es, de constituir en referente del currículum y las lecturas escolares del entorno de que se trate.

De este modo, volvemos a las raíces folclóricas, pues la vida de las damas de agua y de todas las deidades acuáticas también era "anfibia", y se situaba siempre al lado de un manantial, un arroyo, un monte, grutas, cañadas, mares o arboledas. Y entre sus atributos o modus vivendi, está mucho de lo que predican estas corrientes posmodernas: danzar, cantar, solazarse en el agua, etc., con lo cual tradición y modernidad se enlazan, la tradición se preserva y se recrea a la vez.

Una interpretación, literal y figurada a la vez, de fenómenos mitológicos como la autoctonía o la teriantropía o teriomorfismo, lo que nos viene a decir es que el "cordón umbilical" entre el hombre y la naturaleza es fuerte, y que también es fruto de ella todos los seres vivos, incluidos los que la zoomitología catalogaba como "monstruos", esto es, seres singulares, extraordinarios, que son los que en época de Colón poblaban los océanos en el imaginario de los marinos, o, entre los propios griegos, los que poblaban los confines no conocidos, el óros o montes donde deambulan estas criaturas -faunos, licántropos...- junto a las ninfas y dioses de toda índole.

Así pues, este planteamiento se enmarca en una indagación acerca del patrimonio inmaterial de la zona, en conexión con el propio patrimonio natural, la cultura material y los criterios de intervención en función de los vectores políticos, medioambientales, de desarrollo local y urbano, etc. en aplicación.

\subsection{Los Guardianes del Agua}

Según Grebe (2OII) el sentido de estos espíritus del agua es la " preservación del ecosistema incentivando el temor a la aplicación de castigos severos a los transgresores por parte de los espíritus guardianes", y éste es el significado común de los testimonios etnográficos y de las mitologías. 
En la práctica moderna, se ha popularizado en Latinoamérica un tipo de programa de intervención llamado "Guardianes del agua", que trata inculcar en los niños conceptos y actitudes referentes a explicar el ciclo del agua, temas de contaminación, ahorro de agua, etc. Son principios que vemos en campañas de grandes empresas, como Conagua en México o el Canal de Isabel II, en España. En realidad son esquemas de ecoalfabetización basados más en el modelo H2o que en el de Espíritu del Agua (Martínez Dueñas, 20I2). Los problemas son los ya comentados, se sigue invisibilizando la cultura vernácula del agua, ausencia de un discurso narrativo y de un enfoque patrimonial y reivindicativo en conexión con las nuevas narrativas del agua (Barlow, 2008).

La orientación de transversalizar (Pedraza, 2OI2) es buena, lo que suele fallar es la propia praxis educativa, por su restricción al modelo $\mathrm{H}_{2} \mathrm{O}$, dejando en lugar residual los aspectos culturales.

Pongamos un ejemplo significativo de la mitología europea: Medusa, cuya impronta sigue en el folclore español y europeo en numerosos pozos y lugares de memoria (Martos, 20I5). Pensemos en la "monstruosa y mágica" Medusa, que guarda la gran cisterna basílica de Estambul, ejemplo de teriantropía y también de la pugna entre la Diosa de la Vieja Europa de Gimbutas (I99I) y los nuevos valores patriarcales, ya que el convertir en monstruos a estas figuras femeninas constituyó una distorsión interesada.

Así que el estereotipo ha sido el de hacer una lectura "gótica-terrorífica" de estas figuras, soslayando que también son custodios del agua, porque la cuidan y atesoran, y por tanto constituyen una metáfora o imagen conmovedora, identitaria. Es lo que podemos deducir de la Hidra de Lerna, o del dragón que guarda el manantial en los orígenes de la leyenda de San Jorge. Su aspecto está ligado al teriomorfismo, y no revela a priori una naturaleza malvada, de hecho, muchas deidades acuáticas, como Proteo, las sirenas, las xanas o las encantadas, son precisamente teriomorfas, o metamorfas, es decir, tienen algún algún rasgo animal, o pueden cambiar de aspecto cuando se aparecen a los humanos.

\section{$3 \cdot 3$ Ecofeminismo}

La critica ecofeminista ha marcado como solución buscar alternativas, que incluyen contrarrestar el peso racionalista y tecnocrático en la ontología del agua, y posibilitar, en cierto modo, una mirada atrás para "reencantar la naturaleza":

Los ecofeminismos clásicos y espiritualistas insisten en la dimensión de espiritualidad de la naturaleza, cuya negación ha conducido a la civilización al borde de la autodestrucción. Desde estos enfoques, para "sanar a la Madre Tierra" y devolver su magia al mundo, es necesario un proceso que revierta el desencantamiento del mundo señalado por Max Weber como final inevitable del proceso de racionalización europeo. Encantar el mundo implica concebir a éste como sujeto activo, y no como un recurso que puede ser manipulado. Para lograr esta reconceptualización de la existencia, la propuesta consiste en reencantar la naturaleza, que perdió su carácter sagrado cuando surgió la ciencia moderna. (Navarro, 20I6: 80) 
Desde los albores de la humanidad, la Mujer se ha integrado dentro de ciertas constelaciones míticas (mujer-serpiente-luna...), es un hecho comprobado por todos los estudios etnográficos y folklóricos, que vinculan las mujeres a los Imaginarios agropecuarios, esto es, a todo lo relacionados con la fertilidad, el nacimiento o la procreación.

La propia Diosa Madre, arquetipo preindoeuropeo largamente documentado en las culturas europeas, según Gimbutas (I99I), se describe siempre con atributos muy cercanos a la feminidad. Las ninfas, ondinas, y otras de damas de agua del folclore europeo constituyen los avatares de esta diosa madre, reivindicada por las feministas de la Segunda Ola (Simonis, 20I2). Por tanto, hay un paralelismo entre el desarrollo de la cultura del agua en las últimas décadas y el empoderamiento de las mujeres

De hecho, el ecofeminismo ha alumbrado fenómenos como las comunidades ecosociales (Navarro, 20I6), que tienen que ver con una forma de repensar y ejercer el poder femenino que combina la visión ecofeminista con el rescate de tradiciones ancestrales y propuestas espirituales, buscando en suma una visión de continuidad ontológica entre naturaleza y cultura, pues esta dicotomía a lo que ha conducido es a la negación de lo natural y a la exclusión de la mujer

Apelar a la Diosa y al mundo de creencias que describe Gimbutas (I99I), tiene muchas connotaciones que han sido objeto de críticas, pero en todo caso la descripción de Gimbutas habla de un mundo más igualitarias, pacífico y cooperativa que la sociedad patriarcalista clásica, y donde además el discurso de la hegemonía violenta es sustituido por el discurso de la Tierra. De hecho, cuando en las propuestas más recientes se contrasta el discurso de las armas con el discurso de la Tierra, se vuelve en el fondo a esta misma lógica que contrapone Gimbutas entre la simbología, por ejemplo, de los carros de guerra y la de la Diosa, donde la ética del cuidado sobre la naturaleza en su conjunto es prevalente. En efecto, las comunidades ecosociales se caracterizan por un compromiso con "la salud de las mujeres, el pacifismo, los derechos reproductivos, la búsqueda de una nueva espiritualidad no patriarcal, la solidaridad con las mujeres pobres, los derechos de los indígenas, el vegetarianismo y la relación no destructiva de la naturaleza” (Navarro, 20I6:83).

De hecho, en las comunidades ecosociales se ha rescatado el papel de la "guardiana”, esto es, de la mujer encargada de que se vigilen y respeten los elementos tradicionales, por ejemplo, proteger el agua, los peces, etc. (Navarro, 2OI6: I22). Esto choca lógicamente con el modelo consumista de Occidente, pero sin duda es un ejemplo también de lo que está proponiendo la Nueva Cultura del Agua en Occidente: la gestión participativa del agua, ligado al empoderamiento de la comunidad y a la superación del agua como mercancía para orientarla hacia un bien patrimonial compartido. Por tanto, la ciudadanía tiene que participar de esas nuevas narrativas del agua (Barlow, 20o8) y sus propuestas. 


\section{Conclusiones y Propuestas de Futuro}

Como hemos visto a propósito de la conexión entre el saber y la experiencia (Bondia, 2002), la prolijidad de la información es justo lo contrario de la narración arquetípica, los cuentos y leyendas son, precisamente, concisos porque apelan a la experiencia compartida del auditorio. Relatos como el mito de Hilas o algunos cuentos de Grimm, son extremamente cortos, no abundan en datos, apenas que Hilas se acerca a la fuente para llevar agua y desaparece para siempre.

De este modo, el cambio sustancial es que se produce una recategorización del agua tomada no ya como un recurso material que puede ser usado de forma indiscriminado y al servicio exclusivo de intereses individuales y económicos, para convertirse en parte de un patrimonio común (procomún), que requiere por tanto unas nuevas narrativas del agua (Barlow, 20o8). Éstas defienden que el agua no es de nadie sino que pertenece al planeta, a otras especies, a las generaciones futuras y es por tanto un bien público que, gracias a la educación y a las artes, debe ser disfrutado como un bien cultural.

Las ideas de Viveiros sobre multinaturalismo (2004) y de Martínez Dueñas (2OI2), formuladas de la etnografía, enlazan curiosamente con la reflexión del prestigioso neurocientífico P. Sloterdijk (I999). Sus ideas apuntan a la importancia de pensar al hombre en una época posthumanista, poniendo los nexos que hay entre lo humano, la planta, el animal y, moderna, en clave de cibercultura, lo no-humano, el cyborg, la máquina (Villagrán, 2007).

En cambio, para Singer (2009) es posible una ética medioambiental sin religión (Devall y Sessions, 2004), pues esta nueva ética debería relacionarse con la calidad de vida de las personas y de los seres que pueden sentir, de forma, por ejemplo, que evitemos el sufrimiento innecesario, usando para ello la biotecnología.

De tal modo que, sea o no con referentes "espiritualistas" (New Age, Hipótesis Gaia, neopaganismo, Wica, etc.), lo cierto es que reencantar la naturaleza supone considerarla, al igual que los amerindios de que hablaba M. Dueñas (2OI2), como sujeto y por tanto los "lugares de agua" como emplazamientos que corresponden a "lugares sensibles", que compartimos, pero no que dominamos y explotamos conforme a valores antropocéntricos y mercantilistas.

Debemos, pues, revisitar las mitologías vernáculas, en particular porque que ponían en primer plano a la mujer y a la naturaleza, mediante una red de símbolos, como el de las damas de agua y, en concreto, el de las lavanderas nocturnas (Martos, 2OI7), leyenda común a una gran parte del folclore europeo.

Por consiguiente, el reencantamiento de la naturaleza que proponía Navarro (20I6), tiene que pasar por lo defiende la etnoecología (Toledo, 2005), en cuanto a promover a diálogo de saberes que conduzca no a un simple registro etnográfico de creencias, prácticas y textos, sino a su importancia agroecológica. Es decir, los saberes tradicionales sirven para enfrentar los problemas medioambientales actuales (Nassu y Corona, 20I5). Por ejemplo, las leyendas de geniu locilocalizan esos lugares singulares, y episodios como 
inundaciones, raptos, etc. nos hablan metafóricamente de riesgos ambientales, según ya veíamos en el mito odiseico de Escila y Caribdis.

De hecho, el cambio climático y la crisis del agua que cada año se acentúa más, necesitará de esta nueva cultura del agua y de un tratamiento educativo más profundo, unido a un cambio de mentalidad profundo y, por tanto, de innovaciones sociales de calado, como supone poner en valor estas lecturas de la Naturaleza más allá del escaso peso que han venido teniendo. Concluimos con la cita inicial de Barlow: "Sólo redefiniendo nuestra relación con el agua y reconociendo su lugar esencial y sagrado en la naturaleza podremos comenzar a rectificar los errores que hemos cometido". 


\section{Referencias bibliográficas}

- Adiego, V.; Asensio, S. y Serrano, M. A. (2004). Transformando espacios: el aprendizaje de estudiantes no tradicionales en la Educación Superior. Valencia: Universitat de Valencia.

- Aguilar Torres, E. (2015). La ontología múltiple del agua. Mercurio, acueductos comunitarios y territorio en la localidad de ciudad Bolívar (Tesis Doctoral, Universidad Nacional de Colombia-Sede Bogotá).

- Arapoglou, E.; Fodor, M. y Nyman, J. (Eds.). (2013). Mobile narratives: travel, migration, and transculturation (Vol. I8). Abingdon, Reino Unido: Routledge.

-Arrojo, A. P. (2006). El reto ético de la nueva cultura del agua. Barcelona: Paidós.

- Bachelard, G. (2005). El agua y los sueños: ensayo sobre la imaginación de la materia (Vol. I8). México: Fondo de cultura económica

- Bajtín, M. (1974). La cultura popular en la Edad Media y en el Renacimiento. Barcelona: Barral.

- Barlow, M. (2008). El agua, nuestro bien común: hacia una nueva narrativa del agua. México DF: The Council of Canadians, Fundación Heinrich Böll.

- Benjamin, W. (1993). Experiência e pobreza [1933]. Magia e técnica, arte e política. São Paulo: Brasiliense, II4-II9.

- Benjamin, W. (1994). O narrador: considerações sobre a obra de Nikolai Leskov. Magia etécnica, arte e política: ensaios sobre literatura e história da cultura. São Paulo: Brasiliense, I97-22I.

- Bettini, M. (200I). Contra las raíces: Tradición, identidad, memoria. Revista de Occidente, (243), 79-97.

- Bondía Larrosa, J. (2002). Notas sobre a experiência e o saber de experiência. Revista brasileira de educação, (I9).

- Capra, F. (2004). Comprendiendo y vivenciando la ecología. Revista Red del Tercer Mundo, disponible en: wwwredtercermundo

- Chávez, D. H. V. (2OI2). Arquitectura sin arquitectos. Habitar sin destruir: proyecto sobre el habitar vernáculo en la población lacustre de Nueva Venecia (Ciénaga Grande de Santa Marta). Traza, 3(6), 8-I5. 
- Devall, B. y Sessions, G. (2004). Ecologia profunda, dar prioridade à natureza na nossa vida. Águas Santas: Edições Sempre-em-Pé.

- Dourojeanni, A. ; Jouravlev, A. y Chávez, G. (2OO2). Gestión del agua a nivel de cuencas: teoría y práctica (Vol. I). United Nations Publications.

- Eliade, M. (I967). Lo sagrado y lo profano. Madrid: Guadarrama.

- Faust, Franz X., 2004a Un viaje por los paisajes míticos de Colombia. Colombia: Editorial Universidad del Cauca.

- Fernández Guerrero, O. F. (20I0). Cuerpo, espacio y libertad en el ecofeminismo. Nómadas, $27(3), 243^{-256 .}$

- Foucault, M. (I986). Other spaces the principles of heterotopia. Lotus International, 48, 9-I 7 .

- Fructuoso, J. (2006). Breve historia del alma en la Antigüedad. Tonos. Revista Electrónica de Estudios Filológicos XII. Disponible en: https://www.um.es/tonosdigital/znumi2/secciones/Estudios\%2OJ-Alma.htm

- Ghidini, M. T. (20I5). Identidad y mito de la autoctonía en la Grecia antigua. La tierra, los hijos de la tierra. Anales de Historia Antigua, Medieval y Moderna, 49, 5-I4.

- Gimbutas, M. (I99I). The civilization of the Goddess: The world of Old Europe. San Francisco: HarperCollins.

- Gimbutas, M. (i99i). Dioses y diosas de la vieja Europa 7ooo-35oo ac: mitos, leyendas e imagineria. Madrid: Istmo.

- Gonzalez Varela, S.A. (20I5). Antropología y el estudio de las ontologías a principios del siglo XXI: sus problemáticas y desafíos para el análisis de la cultura Época III. Vol. XXI. Número 42, pp. 39-64

- Grebe Vicuña, M. E. (2OII). Algunos paralelismos en los sistemas de creencias mapuches: los espíritus del agua y de la montaña. Chile: Universidad de Chile.

- Honko, L. (Ed.). (200o). Textualization of oralepics (Vol. I28). Berlín: Walter de Gruyter.

- Kinsella, J. (1997). Poems, 1980-1994. Fremantle: Fremantle Arts Centre Press.

- Lafuente, A. (2007). Los cuatro entornos del procomún. Archipiélago. Cuadernos de crítica de la cultura, (77-78), I5-22. 
- Linton, J. (2OIO). What is water? The history of a modern abstraction. Vancouver: UBC Press

- Lovelock, J. (2007). La venganza de Gaia. Barcelona: Editorial Planeta.

- Martínez Dueñas, W. (2OI2a). Quand $\mathrm{H}_{2} \mathrm{O}$ et esprit de l'eau se rencontrent: Coexistence de plusieurs mondes à Puracé, Colombie. Recherches amérindiennes au Québec, 42(2-3).

- Martínez Dueñas, W. (20I2b). Cosmopolitismo ambiental y redes multinaturales: un recorrido por mundos no [tan] modernos en Puracé, Colombia. Tesis de Doctorado en Antropología. Colombia: Universidad del Cauca.

- Martos García, A. (20I5). Imaginarios clásicos y nuevas lecturas de las leyendas de tesoros. Opción, 3I(78).

- Martos García, A. y Martos García, A. (20I5). Nuevas lecturas de la llorona: imaginarios, identidad y discurso parabólico. Universum (Talca), 3O(2), I79-I95.

- Martos Nuñez, E. M. y García, A. M. (2Oı6). Zooiconología y literatura. Imágenes de los animales entre la tradición folklórico-literaria, las artes y el simbolismo. Edetania, 49, 75-89

- Martos Nuñez, E. M. y Martos García, A. (20I7). Literatura, folclore y medio ambiente: el caso de las lavanderas. Textura-Ulbra, ı9 (39), pp 6-I8.

- Martos Núñez, E. y Martos García, A. (2OII). Memorias y mitos del agua en la Península Ibérica. Madrid: Marcial Pons.

- Merchán, J. S. (2OII). ¿Qué hay de malo en la biotecnología? La ecología profunda y el reencantamiento de la naturaleza. Grafía, (8), IOI-I26.

- Morales Gómez, J. (2002). Los encantos: escenarios de relaciones interétnicas. Boletín Museo del Oro, (50).

- Nassu Vargas, Y. y Corona, E. (2015) Recuperando el conocimiento tradicional para enfrentar los problemas ambientales actuales. A propósito de la Etnoecología incluyente. El Tlacuache, $685,3-4$

- Navarro Casillas, A. M. (20I6). Análisis de la reflexividad de las comunidades ecosociales de mujeres como agentes de cambio cultural, Tesis Doctoral, U. Autónoma de Aguascalientes

- Norberg-Schulz, C. (1979). Genius loci: paesaggio ambiente architettura. Milano: Electa, No. 72.OI.

- Otto, R. (I965). Lo santo: Lo racionaly lo irracional en la idea de Dios. Madrid: Alianza. 
- Pedraza Contreras, M. L. (2012). Agua que nos habita: una propuesta de transversalización de la cultura del agua en la Institución Educativa Rural Yarumito (Tesis Doctoral, Universidad Nacional de Colombia, Medellín).

- Pérez Blanco, L. (20I7). Arquitectura hilozoica y espacio sensible. Madrid: E.T.S. Arquitectura (UPM).

- Redondo-Olmedilla, J. C. (2OI5). A Companion to Australian Aboriginal Literature edited by Belinda Wheeler. The Goose, I4(I), 39 .

- Revilla Orías, P. (20I2). Quesintuu y Umantuu: Sirenas y memoria andina. Runa, 33(2), I33-I 55 .

- Reynoso, C. (2015). Crítica de la antropología perspectivista: Viveiros de Castro-Philippe Descola-Bruno Latour. Caba, Argentina: SB editorial.

- Shiva, V. S. M. (2006). Manifiesto para una democracia de la tierrajusticia, sostenibilidad y paz, Barcelona: Paidós.

- Silvestri, G. (20I5). Las heterotopías felices. Anales del Instituto de Arte Americano N. 44

- Simonis Sampedro, A. (2OI2). La Diosa feminista: el movimiento de espiritualidad de las mujeres durante la Segunda Ola. Feminismo/s, (2O), 25-42.

- Singer, P. (2009). Ética práctica (Vol. 13). Madrid: Ediciones Akal.

- Sloterdijk, P. (ı999, July). Reglas para el Parque Humano: una respuesta a la "Carta sobre el Humanismo". In Conferencia pronunciada en el castillo de Elmau, Baviera.

- Toledo, V. M. (2005). La memoria tradicional: la importancia agroecológica de los saberes locales. Leisa Revista de agroecología, 20(4), I6-I9.

- Tuan, Y. F. (2OI3). Landscapes offear. New York: Pantheon.

- Vila, J. L. P.; de la Cuesta, G. S. y Jiménez, C. P. (I977). La Calidad del agua, el fenómeno comunitario y la salud. Academia de Medicina.

- Villagrán, C. (20O7). Sloterdijk y la ontogénesis del ser humano; la planta y el animal que hay en nosotros. Observaciones Filosóficas. Chile: PUCV.

- Viveiros de Castro, E. (2004). Perspectivismo y multinaturalismo en la América indígena. Tierra adentro: Territorio indígena y percepción del entorno, 37. 